\title{
Visualization of Surface Antigens on Yeast Protoplasts by Gold or Ferritin Markers
}

\author{
Masashi Yamaguchi and Tadashi Hirano \\ Central Research Laboratory, The Jikei University School of Medicine, Minato- \\ ku, Tokyo 105, Japan
}

\begin{abstract}
Surface antigens of Saccharomyces cerevisiae protoplast were visualized immunocytochemically with protein A-gold or ferritin conjugated antibodies. Ferritin particles were densely distributed at the surface of yeast protoplast after treatment with rabbit anti-protoplast serum and ferritin conjugated antibody against rabbit IgM. Control experiments demonstrated that the binding of these ferritin markers was specific for surface antigens. The composition of these surface antigens, however, remain to be investigated.
\end{abstract}

Yeast protoplasts have been widely used for cell fusion or DNA transformation $(6,7)$, but so far, few cytological investigations have been undertaken. We previously investigated the surface ultrastructure, especially that of invaginations, of yeast protoplasts $(2,4)$. We also demonstrated using cationized ferritin that the yeast protoplast surface was negatively charged (3). The purpose of the present study was to visualize surface antigens of yeast protoplasts and examine their distribution immunocytochemically with gold or ferritin markers.

\section{MATERIALS AND METHODS}

Saccharomyces cerevisiae $8256\left(\mathrm{a}\right.$, ade $\left.^{-}\right)$was grown in YPD medium $(1 \%$ yeast extract, $2 \%$ pepton, $2 \%$ dextrose) with agitation at $30^{\circ} \mathrm{C}$ to the late logarithmic phase. To prepare protoplasts, the cells were treated with Zymolyase $60,000(0.1 \mathrm{mg} / \mathrm{ml}$, Kirin brewry Co., Japan) in $0.8 \mathrm{M}$ sorbitol for $60 \mathrm{~min}$ at $30^{\circ} \mathrm{C}$. Antiserum was prepared by injecting rabbits with a formalin-fixed protoplast suspension 5 times at 5-7 day intervals. Rabbits were bled completely one week after the final injection. The serum was used after the complement had been inactivated.

To visualize surface antigens, protoplasts were fixed with $3 \%$ glutaraldehyde for $60 \mathrm{~min}$ at $4{ }^{\circ} \mathrm{C}$, washed with PBS $(0.9 \% \mathrm{NaCl}-10 \mathrm{mM}$ phosphate buffer, $\mathrm{pH} 7.4)$, and treated with rabbit antiserum $\left(1 / 2\right.$ dilution) for $60 \mathrm{~min}$ at $37^{\circ} \mathrm{C}$. The suspension was washed with PBS and treated for $30 \mathrm{~min}$ at $37^{\circ} \mathrm{C}$ with one of the following markers; a) protein A-gold (pAg, 10-15 nm in diameter, E-Y Lab., U.S.A., 1/5 dilution), b) ferritin conjugated antibody against rabbit IgG (Fe-IgG, Cappel Lab., U.S.A., 1/20 dilution), or c) ferritin conjugated antibody against rabbit IgM (Fe-IgM, Cappel Lab., U.S.A., 1/20 dilution). The sample was then post-fixed with $\mathrm{OsO}_{4}$, dehydrated with a graded series of ethanols, and embedded in Epon

Abbreviations used: pAg, protein A-gold; Fe-IgG, ferritin conjugated antibody against rabbit immunoglobulin G; Fe-IgM, ferritin conjugated antibody against rabbit immunoglobulin M. 
812. Ultrathin sections were cut with a Reichert-Jung OmU4 ultramicrotome, stained with uranyl acetate and lead citrate, and examined in a JEOL 1200EX or 100S electron microscope. For controls, protoplasts were also treated as follows; 1) with normal rabbit serum and $\mathrm{pAg}, \mathrm{Fe}-\mathrm{IgG}$ or $\mathrm{Fe}-\mathrm{IgM}$, 2) with pAg, Fe-IgG or Fe-IgM only, 3) with rabbit antiserum only, or 4) with no treatment (intact protoplast).

\section{RESULTS AND DISCUSSION}

The surface of intact yeast protoplasts was smooth and invaginations characteristic to yeast cells were observed (Fig. 1). No residual cell wall material was detected. The thickness of the plasma membrane was about $9.9 \mathrm{~nm}$ (average of 10 measurements). Following treatment with rabbit antiserum and pAg, gold particles were randomly distributed on the surface of the protoplasts (Fig. 2). When treated with rabbit antiserum and $\mathrm{Fe}-\mathrm{IgG}$, distribution of ferritin particles was again random (Fig. 3). Labeling density of these markers seemed to be rather low. After treatment with rabbit antiserum and $\mathrm{Fe}-\mathrm{IgM}$, however, ferritin particles were densely distributed on the protoplast surface (Fig. 4a, 4b). These ferritin markers were located at least 20-30 $\mathrm{nm}$ above the surface of plasma membrane, and there was flocculent material between them and the membrane (Fig. 4b). This flocculent material may consist of antibodies bound to surface antigens, because no such material was observed when

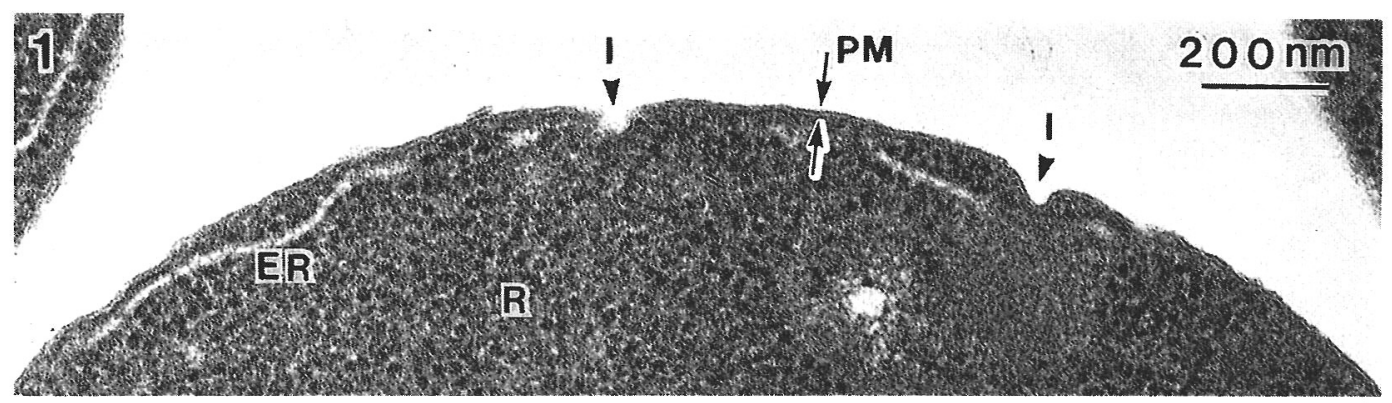

Fig. 1. Ultrathin section of an intact Saccharomyces cerevisiae protoplast. PM: plasma membrane, I: invaginations, ER: endoplasmic reticulum, R: ribosomes. $\times 64,000$.

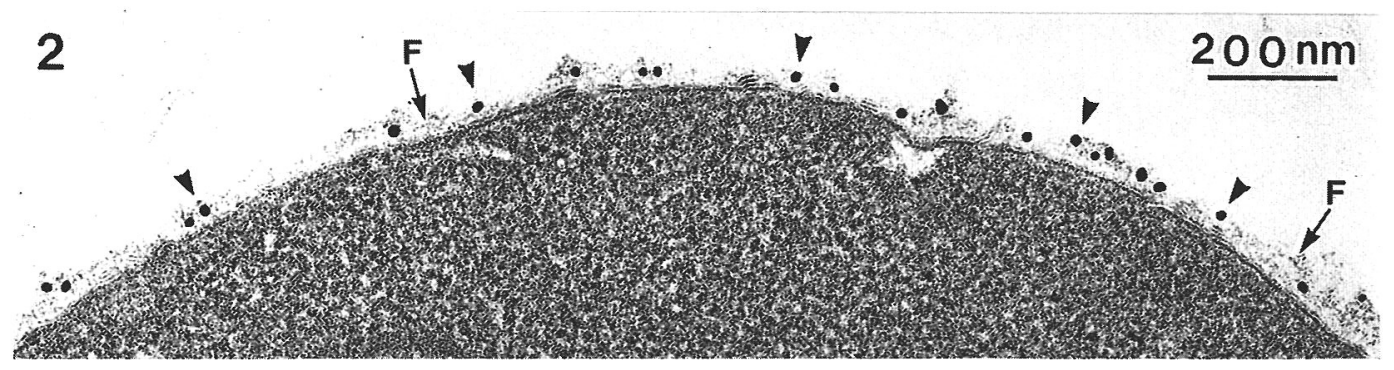

Fig. 2. A S. cerevisiae protoplast that was treated with rabbit anti-protoplast serum and protein A-gold. Gold markers (arrow heads) were randomly distributed on the surface of the protoplast. F: flocculent material. $\times 64,000$. 


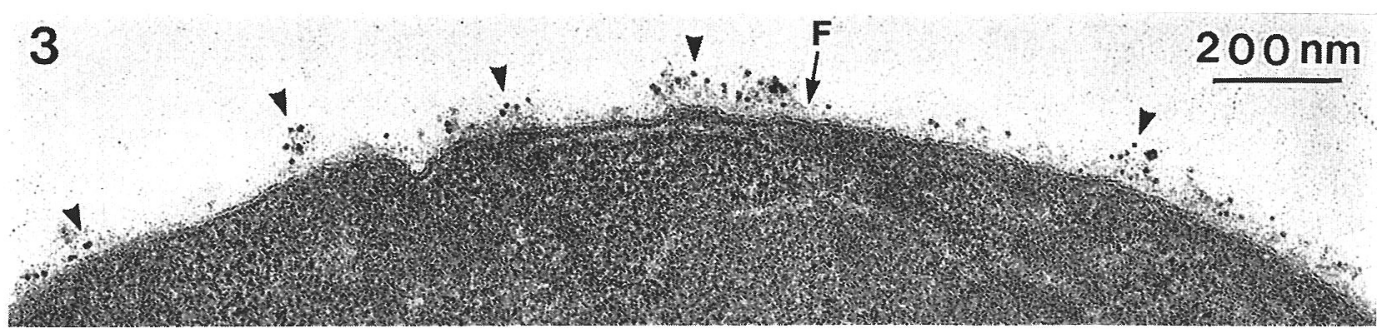

Fig. 3. A S. cerevisiae protoplast that was treated with rabbit anti-protoplast serum and ferritin conjugated antibody against rabbit IgG. The distribution of ferritin markers (arrow heads) was again random. F: flocculent material. $\times 64,000$.
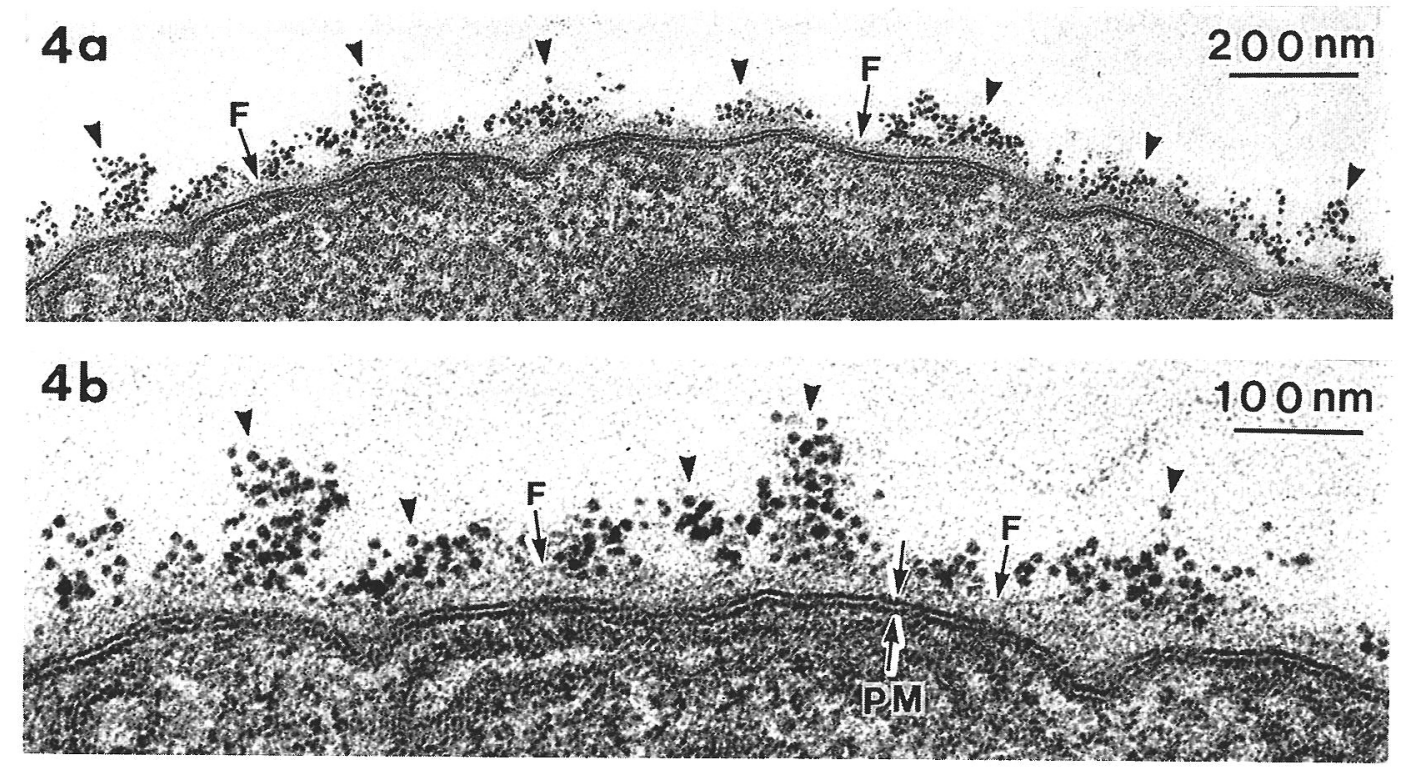

Fig. 4. A S. cerevisiae protoplast that was treated with rabbit anti-protoplast serum and ferritin conjugated antibody against rabbit IgM. Ferritin markers (arrow heads) were densely distributed on the surface of the protoplast. F: flocculent material, PM: plasma membrane. a) $\times 64,000$, b) $\times 128,000$.

protoplasts were treated with normal rabbit serum and Fe-IgM, and because a similar material was observed after treatment of glutaraldehyde-fixed protoplasts with complement-inactivated antiserum only, with antiserum and pAg (Fig. 2), or with antiserum and Fe-IgG (Fig. 3). Few ferritin particles were found when protoplasts were treated with normal rabbit serum and Fe-IgM, or Fe-IgM alone, demonstrating that the binding of ferritin markers seen in Fig. 4 is specific for surface antigens.

Protein A-gold is known to bind rabbit immunoglobulin G (1). Since both pAg and Fe-IgG bind rabbit immunoglobulin $\mathrm{G}$ and $\mathrm{Fe}-\mathrm{IgM}$ binds rabbit immunoglobulin M, low labeling density with pAg (Fig. 2) (8) or Fe-IgG (Fig. 3) and high 
labeling density with Fe-IgM (Fig. 4a, 4b) may indicate that the antiserum used in this study contained less immunoglobulin of the $\mathrm{G}$ class and more immunoglobulin of the $\mathrm{M}$ class.

Horisberger et al. reported the existance of mannan on the surface of yeast protoplasts (5). However, other surface antigens of yeast protoplasts are not examined immunocytochemically and need to be investigated.

Acknowledgments. The authors wish to thank Emeritus Professor Isamu Kondo for valuable suggestions and discussion. We also thank Mr. Michio Hoshino, Miss Emi Matsumoto and Mr. Hideki Saito for their technical assistance. This study was supported in part by Grant-in-Aid No. 60740388 from the Ministry of Education, Science and Culture, Japan.

\section{REFERENCES}

1. Goudswat, J., J.A. Van der Donk, A. NoordziJ, R.H. Van Dam and J.-P. Vaerman. Protein A reactivity of various mammalian immunoglobulins. Scand. J. Immunol. 8, 21-28, 1978

2. Hirano, T. and A. TAnaka. Surface ultrastructure of the yeast protoplast. in Advances in Protoplast Research, ed. Ferenczy, L. and G.L. Farkas, Pergamon Press, Oxford, pp. 163-170, 1980

3. Hirano, T., M. Yamaguchi, A. Tanaka and Y. Sekiguchi. Localization of cationized ferritin on surface of yeast protoplasts. Cell Struct. Funct. 7, 440, 1982

4. Hirano, T. Yeast protoplasts. Saibo 16, 15-21, 1984

5. Horisberger, M., J. Rosset and H. Bauer. Localization of mannan at the surface of yeast protoplasts by scanning electron microscopy. Arch. Microbiol. 109, 9-14, 1976

6. Miyanohara, A., A. Toh-e, C. Nozaki, F. Hamada, N. Ohtomo and K. Matsubara. Expression of hepatitis B surface antigen gene in yeast. Proc. Natl. Acad. Sci. U.S.A. 80, 1-5, 1983

7. Spencer, J.F.T. and D.M. Spencer. Genetic improvement of industrial yeasts. Ann. Rev. Microbiol. 37, 121-142, 1983

8. Yamaguchi, M., T. Hirano, T. Tachibana and A. TanaKa. Electron microscopy of surface antigens on yeast protoplasts by the plasma polymerization-film metal extraction replica method. J. Electron Microsc. 34, 169-173, 1985

(Received for publication, December 4, 1986) 